\title{
Think globally, measure locally: The MIREN standardized protocol for monitoring species distributions along elevation gradients
}

Sylvia Haider ${ }^{1}$, Jonas Lembrechts ${ }^{2}$, Keith McDougall ${ }^{3}$, Anibal Pauchard ${ }^{4}$, Jake M. Alexander ${ }^{5}$, Agustina Barros ${ }^{6}$, Lohengrin Cavieres ${ }^{4}$, Irfan Rashid ${ }^{7}$, Lisa Rew ${ }^{8}$, Alla Aleksanyan $^{9}$, José Arevalo Sierra ${ }^{10}$, Valeria Aschero ${ }^{11}$, Chelsea Chisholm ${ }^{5}$, Vincent Ralph Clark $^{12}$, Jan Clavel $^{2}$, Curtis Daehler ${ }^{13}$, Pervaiz Dar ${ }^{14}$, Hansjoerg Dietz ${ }^{15}$, Romina Dimarco $^{16}$, Peter Edwards ${ }^{17}$, Franz Essl ${ }^{18}$, Eduardo Fuentes-Lillo ${ }^{19}$, Antoine Guisan ${ }^{20}$, Onalenna Gwate ${ }^{21}$, Anna Hargreaves ${ }^{22}$, Gabi Jakobs ${ }^{5}$, Alejandra Jiménez ${ }^{23}$, Paul Kardol ${ }^{24}$, Cristoph Küffer ${ }^{25}$, Christian Larson ${ }^{26}$, Jonathan Lenoir ${ }^{27}$, Bernd Lenzner ${ }^{18}$, Miguel Padrón Mederos $^{28}$, Maritza Mihoc ${ }^{19}$, Ann Milbau ${ }^{29}$, John Morgan ${ }^{30}$, Jana Müllerová ${ }^{31}$, Bridgett Naylor ${ }^{32}$, Ivan Nijs ${ }^{2}$, Martin Nuñez ${ }^{33}$, Rüdiger Otto ${ }^{34}$, Davnah Payne ${ }^{35}$, Niels Preuk ${ }^{36}$, Amanda Ratier Backes ${ }^{36}$, ZAFAR A. RESHI ${ }^{7}$, Sabine Rumpf ${ }^{20}$, Verónica Sandoya ${ }^{37}$, Mellesa Schroder ${ }^{38}$, Karina Speziale ${ }^{39}$, Graciela Valencia ${ }^{19}$, Vigdis Vandvik ${ }^{40}$, Michaela Vítková $^{41}$, Tom Vorstenbosch ${ }^{18}$, Tom Walker ${ }^{5}$, Neville Walsh ${ }^{42}$, Genevieve Wright ${ }^{43}$, Shengwei Zong ${ }^{44}$, and Tim Seipel ${ }^{45}$

${ }^{1}$ Martin Luther University Halle Wittenberg

${ }^{2}$ University of Antwerp

${ }^{3}$ Research Centre for Applied Alpine Ecology

${ }^{4}$ Universidad de Concepcion

${ }^{5}$ ETH Zürich

${ }^{6}$ Centro Científico Tecnológico Mendoza

${ }^{7}$ University of Kashmir

${ }^{8}$ Montana State University

${ }^{9}$ National Academy of Sciences of the Republic of Armenia

${ }^{10}$ University of La Laguna

${ }^{11}$ Universidad Nacional de Cuyo

${ }^{12}$ University of the Free State - Qwaqwa Campus

${ }^{13}$ University of Hawai'i

${ }^{14}$ Amar Singh PG College

${ }^{15}$ ETH Zurich

${ }^{16}$ Instituto de Investigaciones Forestales y Agropecuarias Bariloche (IFAB)

${ }^{17}$ Swiss Federal Institute of Technology (ETH)

${ }^{18}$ University of Vienna

${ }^{19}$ Universidad de Concepción

${ }^{20}$ University of Lausanne

${ }^{21}$ University of the Free State

${ }^{22}$ McGill University 
${ }^{23}$ Universidad de Chile Instituto de Ecología y Biodiversidad

${ }^{24}$ Swedish University of Agricultural Sciences

${ }^{25}$ Institute of Integrative Biology

${ }^{26}$ Montana State University Bozeman

${ }^{27}$ CNRS Delegation Nord Pas-de-Calais et Picardie

${ }^{28}$ Universidad de La Laguna

${ }^{29}$ Research Institute for Nature and Forest

${ }^{30}$ La Trobe University

${ }^{31}$ Institute of Botany Czech Academy of Sciences

${ }^{32}$ US Forest Service

${ }^{33}$ Universidad Nacional del Comahue

${ }^{34}$ University of La Laguna Tenerife

${ }^{35}$ University of Bern

${ }^{36}$ Martin-Luther-Universitat Halle-Wittenberg

${ }^{37}$ University Yachay Tech

${ }^{38}$ New South Wales National Parks \& Wildlife Service

${ }^{39}$ Instituto de Investigaciones en Biodiversidad y Medioambiente

${ }^{40}$ University of Bergen

${ }^{41}$ Czech Academy of Sciences

${ }^{42}$ Royal Botanic Gardens Victoria

${ }^{43}$ New South Wales Department of Planning Industry and Environment

${ }^{44}$ Northeast Normal University

${ }^{45}$ Montana State University System

May 28, 2021

\begin{abstract}
Climate change and other global change drivers threaten plant diversity in mountains worldwide. A widely documented response to such environmental modifications is for plant species to change their elevational ranges. Range shifts are often idiosyncratic and difficult to generalize, partly due to variation in sampling methods. There is thus a need for a standardized monitoring strategy that can be applied across mountain regions to assess distribution changes and community turnover of native and non-native plant species over space and time. Here, we present a conceptually intuitive and standardized protocol developed by the Mountain Invasion Research Network (MIREN) to systematically quantify global patterns of native and non-native species distributions along elevation gradients and shifts arising from interactive effects of climate change and human disturbance. Usually repeated every five years, surveys consist of 20 sample sites located at equal elevation increments along three replicate roads per sampling region. At each site, three plots extend from the side of a mountain road into surrounding natural vegetation. The protocol has been successfully used in 18 regions worldwide from 2007 to present. Analyses of one point in time already generated some salient results, and revealed region-specific elevational patterns of native plant species richness, but a globally consistent elevational decline in non-native species richness. Non-native plants were also more abundant directly adjacent to road edges, suggesting that disturbed roadsides serve as a vector for invasions into mountains. From the upcoming analyses of time series even more exciting results especially about range shifts can be expected. Implementing the protocol in more mountain regions globally would help to generate a more complete picture of how global change alters species distributions. This would inform conservation policy in mountain ecosystems, where some conservation policies remain poorly implemented.
\end{abstract}

Think globally, measure locally:The MIREN standardized protocol for monitoring species distributions along elevation gradients 
Sylvia Haider ${ }^{1,2, \mathrm{x}}$, Jonas J. Lembrechts ${ }^{3, \mathrm{x}}$, Keith McDougall ${ }^{4}$, Aníbal Pauchard ${ }^{5,6}$, Jake M. Alexander ${ }^{7}$, Agustina Barros 8 , Lohengrin A. Cavieres ${ }^{9,6}$, Irfan Rashid ${ }^{10}$, Lisa J. Rew ${ }^{11}$, Alla Aleksanyan ${ }^{12,13}$, José R. Arévalo $^{14}$, Valeria Aschero ${ }^{8}$, Chelsea Chisholm ${ }^{7}$, V. Ralph Clark ${ }^{15}$, Jan Clavel $^{3}$, Curtis Daehler ${ }^{16}$, Pervaiz A. Dar ${ }^{17}$, Hansjörg Dietz ${ }^{7}$, Romina D. Dimarco ${ }^{18}$, Peter Edwards ${ }^{7}$, Franz Essl ${ }^{19}$, Eduardo FuentesLillo $^{5,20,21}$, Antoine Guisan ${ }^{22}$, Onalenna Gwate ${ }^{15}$, Anna Hargreaves ${ }^{23}$, Gabi Jakobs ${ }^{7}$, Alejandra Jiménez ${ }^{24}$, Paul Kardol ${ }^{25,26}$, Christoph Kueffer ${ }^{7,27}$, Christian Larson ${ }^{11}$, Jonathan Lenoir ${ }^{28}$, Bernd Lenzner ${ }^{19}$, Miguel A. Padrón Mederos ${ }^{29}$, Maritza Mihoc ${ }^{30}$, Ann Milbau ${ }^{31}$, John W. Morgan ${ }^{32}$, Jana Müllerováa ${ }^{33}$, Bridgett Naylor $^{34}$, Ivan Nijs ${ }^{3}$, Martin A. Nuñez ${ }^{35}$, Rüdiger Otto ${ }^{14}$, Davnah Payne ${ }^{36}$, Niels Preuk ${ }^{1}$, Amanda Ratier Backes $^{1,2}$, Zafar A. Reshi ${ }^{10}$, Sabine B. Rumpf ${ }^{37}$, Verónica Sandoya ${ }^{38,39,40}$, Mellesa Schroder ${ }^{41}$, Karina L. Speziale $^{42}$, Graciela Valencia ${ }^{30}$, Vigdis Vandvik ${ }^{43}$, Michaela Vitková ${ }^{44}$, Tom Vorstenbosch ${ }^{19,45}$, Tom W.N. Walker $^{7}$, Neville Walsh ${ }^{46}$, Genevieve Wright ${ }^{47}$, Shengwei Zong ${ }^{48}$, Tim Seipel ${ }^{11}$

${ }^{\mathrm{x}} \mathrm{SH}$ and JJL contributed equally to this manuscript and wish to be considered joint first authors.

*Corresponding author: sylvia.haider@botanik.uni-halle.de

Affiliations:

1) Martin Luther University Halle-Wittenberg, Institute of Biology / Geobotany and Botanical Garden, Am Kirchtor 1, 06108 Halle, Germany,

2) German Centre for Integrative Biodiversity Research (iDiv) Halle-Jena-Leipzig, Puschstr. 4, 04103 Leipzig, Germany,

3) Research group Plants and Ecosystems (PLECO), University of Antwerp, Universiteitsplein 1, 2610 Wilrijk, Belgium,

4) Department of Planning, Industry and Environment, PO Box 733, Queanbeyan, NSW, 2620 Australia,

5) Laboratorio de Invasiones Biologicas (LIB), Facultad de Ciencias Forestales, Universidad de Concepción, Concepción, Chile,

6) Institute of Ecology and Biodiversity (IEB), Santiago, Chile,

7) Institute of Integrative Biology, ETH Zürich, 8092 Zürich, Switzerland,

8) Instituto Argentino de Nivología y Glaciología y Ciencias Ambientales (IANIGLA), Centro Científico Tecnológico (CCT), CONICET Mendoza, Av. Ruiz Leal s/n, C.C 330, Mendoza, Argentina,

9) Departamento de Botánica, Facultad de Ciencias Naturales y Oceanográficas, Universidad de Concepción, Concepción, Chile,

10) Department of Botany, University of Kashmir, Srinagar - 190006, Jammu and Kashmir, India,

11) Department of Land Resource and Environmental Sciences, Montana State University, Bozeman Montana, USA,

12) Department of Geobotany and Plant Ecophysiology, Institute of Botany aft. A.L. Takhtajyan NAS RA, Acharyan 1, 0040, Yerevan Armenia,

13) Chair of Biology and Biotechnologies, Armenian National Agrarian University, Teryan 74, 0009, Yerevan Armenia,

14) Department of Botany, Ecology and Plant Physiology, University of La Laguna, La Laguna 38202, Spain,

15) Afromontane Research Unit \& Department of Geography, University of the Free State: Qwaqwa Campus, Phuthaditjhaba, Free State, South Africa,

16) University of Hawai'i at Manoa, School of Life Sciences, 3190 Maile Way Honolulu, HI 96822,

17) Department of Botany, Amar Singh College Srinagar, India-190008, 
18) Grupo de Ecología de Poblaciones de Insectos, IFAB (INTA-CONICET), Bariloche, Rio Negro, Argentina,

19) Bioinvasions, Global Change, Macroecology-Group, Department of Botany and Biodiversity Research, University Vienna, Rennweg 14, 1030 Vienna, Austria,

20) Plants and Ecosystems Research Center (PLECO), University of Antwerp, Universiteitsplein 1, 2610 Wilrijk, Belgium,

21) School of Education and Social Sciences, Adventist University of Chile, Chile,

22) Institute of Earth Surface Dynamics \& Department of Ecology and Evolution, University of Lausanne, 1015 Lausanne, Switzerland,

23) Department of Biology, McGill University, 1205 Av Dr Penfield, Montreal QC, Canada H3A 1B1,

24) Laboratorio de Invasiones Biologicas (IEB). Instituto de Ecologia y Biodiversidad (IEB), Santiago, Chile,

25) Department of Forest Ecology and Management, Swedish University of Agricultural Sciences, 901-83, Umea, Sweden,

26) Instituto de Ecologia y Biodiversidad (IEB), Santiago, Chile,

27) Department of Botany and Zoology, Centre for Invasion Biology, Stellenbosch University, Matieland, South Africa,

28) UR "Ecologie et Dynamique des Systemes Anthropises" (EDYSAN, UMR 7058 CNRS), Universite de Picardie Jules Verne, 1 Rue des Louvels, 80000 Amiens, France,

29) Departamento de Botanica, Ecologia y Fisiologia Vegetal-Area de Ecologia (Universidad de La Laguna). Avenida Astrofisico Francisco Sanchez, s/n. 38200. San Cristobal de La Laguna. S/C de Tenerife,

30) Instituto de Ecologia y Biodiversidad (IEB). Chile,

31) Research Institute for Nature and Forest - INBO, 1000 Brussels, Belgium,

32) Department of Ecology, Environment and Evolution, La Trobe University, Bundoora VIC 3086, Australia,

33) Department of GIS and Remote Sensing, Institute of Botany of the Czech Academy of Sciences, Zamek 1, 25243 Pruhonice, Czech Republic,

34) US Forest Service, PNW Research Station, 1401 Gekeler Lane, La Grande OR 97850,

35) Grupo Ecologia de Invasiones. Instituto de Investigaciones en Biodiversidad y Medio Ambiente, CONICET - Universidad Nacional del Comahue, Bariloche, Rio Negro, Argentina,

36) Global Mountain Biodiversity Assessment, University of Bern, Institute of Plant Sciences, Altenbergrain 21, CH - 3013 Bern, Switzerland,

37) Department of Ecology and Evolution, University of Lausanne, Biophore, 1015 Lausanne, Switzerland,

38) Yachay Tech University, School of Life Sciences and Biotechnology, Hda. San Jose s/n y Proyecto Yachay, 100119, Urcuqui, Ecuador,

39) CREAF, Cerdanyola del Valles 08193, Spain,

40) Unitat d'Ecologia, Universitat Autonoma de Barcelona, Cerdanyola del Valles 08193, Spain,

41) Department of Planning, Industry and Environment, Jindabyne, Kosciuszko Rd (PO Box 2228), Jindabyne 2627 ,

42) Laboratorio Ecotono, INIBIOMA (CONICET-UNCOMA), Pasaje Gutierrez 1125 (8400), Bariloche, Argentina, 
43) Department of Biological Sciences, University of Bergen, Tormohlensgate 53A, Bergen, Norway,

44) Department of Invasion Ecology, Institute of Botany of the Czech Academy of Sciences, Zamek 1, CZ-252 43 Průhonice, Czech Republic,

45) Institute of Biology Leiden, Leiden University, Sylviusweg 72, 2333 BE, Leiden, Netherlands,

46) Royal Botanic Gardens Victoria, Birdwood Avenue, Melbourne Victoria 3004,

47) NSW Government, Biodiversity and Conservation, Department of Planning, Industry and Environment, PO Box 514, 11 Farrer Place, Queanbeyan NSW 2620,

48) Key Laboratory of Geographical Processes and Ecological Security in Changbai Mountains, Ministry of Education, School of Geographical Sciences, Northeast Normal University, Changchun 130024, China

\section{Introduction}

Mountains are biodiversity hotspots and provide a wealth of ecosystem functions and benefits to people (Körner \& Spehn, 2002; Martín-López et al., 2019; Mengist et al., 2020). At the same time, mountain ecosystems are particularly susceptible to global change. For instance, temperatures are increasing faster at high elevation than at low elevation (Nogués-Bravo et al., 2007; Pepin et al., 2015). In the alpine zone of the European Alps, temperatures have increased approximately twice as much as the northern hemisphere average over the past 100 years (Gobiet et al., 2014). Importantly, amplified warming has enabled many plant species to move to higher elevation (Lenoir et al., 2008; Pauli et al., 2012; Steinbauer et al., 2018). For instance, between 1971 and 1993 native plant species from the forest understorey in the French mountains shifted their elevational range uphill at an average rate of $38 \mathrm{~m}$ per decade (Lenoir et al. 2008). Another prominent example is the observed upward shift of most vascular taxa at Chimborazo in Ecuador since Alexander von Humboldt's visit more than two centuries ago (Morueta-Holme et al., 2015). An expected consequence of such uphill migrations of more competitive lowland species is that less competitive alpine species might locally extinct on mountain summits (Dullinger et al., 2012; Alexander et al., 2018; Guisan et al., 2019; Rumpf et al., 2019). Such local extinctions were recently documented for birds (e.g. Freeman et al., 2018).

In addition to temperature increase, human activities in mountain areas have changed markedly over the last decades (e.g. Peters et al., 2019; Wang et al., 2019; for an overview see Payne et al., 2020). Mountain land use has intensified in many places across the globe (Spehn et al., 2006), driven by booming tourism industries (Pickering \& Barros, 2012; Debarbieux et al., 2014), overexploitation of natural resources and ever-increasing demands for agricultural land (e.g. Gillet et al., 2016; Ross et al., 2017). The abandonment of traditional cutting and grazing practices has also occurred in some mountain regions (e.g. MacDonald et al., 2000). Both land use intensification and abandonment can alter plant species distributions and diversity alone (Pellissier et al., 2013; Alexander et al., 2016) and by interacting with climate change (Guo et al., 2018; Elsen et al., 2020).

Further, previously remote areas are becoming increasingly accessible due to construction of new roads and trails, which not only cause a direct disturbance, but also act as corridors for plant species movements (Ansong \& Pickering, 2013; Lembrechts et al., 2017; Rew et al., 2018). The role of roads as dispersal corridors is amplified due to increased vehicle traffic, often as a result of recreation and tourism (e.g. Müllerová et al., 2011). Roadside habitats also provide ideal spaces for non-native plants, which generally benefit from reduced competition, increased soil nutrients, more favourable microclimatic and hydrological conditions and intermediate disturbance (Müllerová et al., 2011; Averett et al., 2016). Thus, both native and nonnative plant species are known to disperse along mountain roads, from low to high elevation and vice versa (Dainese et al., 2017; Lembrechts et al., 2017; Guo et al., 2018). Indeed, many high elevation areas once free of lowland and non-native species but connected to lowlands by road networks are now harbouring lowland and non-native plant species. Examples for this are the volcanoes of the Hawaiian archipelago (Jakobs et al., 2010), the high Andes (Barros et al., 2020) and the Teide National Park on Tenerife (Dickson et al., 1987). 
Roadside habitats are also conduits for non-native plants to spread into natural vegetation once established along roadsides (Alexander et al., 2011; Seipel et al., 2012).

The elevational redistribution of plant species, especially non-native species (Dainese et al., 2017), has already significantly impacted mountain ecosystems (Guo et al., 2018) and will continue to do so in the future (Petitpierre et al., 2016). For example, non-native plants can cause biotic homogenization (Haider et al., 2018), reduce the diversity of local native species (Daehler, 2005) and affect important ecosystem functions and services (McDougall et al., 2011b; Pecl et al., 2017). In the mountains of Iceland, non-native Lupinus nootkatensiscompetes strongly with native plant species and modifies soil properties through nitrogen fixation (Wasowicz, 2016). In the alpine zone of the central Chilean Andes, non-native Taraxacum officinale shares pollinators with several native Asteraceae species (Muñoz \& Cavieres, 2019), reducing pollinator-visitation rates and seed-set where T. officinale is at high abundances (Muñoz \& Cavieres, 2008). Finally, uphill migration of non-native trees and shrubs can increase fire risk at high elevation (Cóbar-Carranza et al., 2014), and transform plant communities through competition (Zong et al., 2016; Nuñez et al., 2017).

While human-driven vegetation change can happen relatively quickly in mountains, it often only becomes apparent at temporal scales beyond the few years covered by most ecological experiments (Mirtl et al., 2018). Thus, data from long-term time series in mountains are essential to identify and follow changes in plant communities (Pauli et al., 2012). There are currently two main types of initiatives which monitor high-elevation vegetation change. At the local or regional scale, some well-established long-term monitoring sites follow a holistic approach and document not only floristic changes, but also modifications for example of soil, hydrology or atmospheric conditions. Examples are Niwot Ridge in the Colorado Rocky Mountains (www.nwt.lternet.edu) or the Sierra Nevada Global Change Observatory in Spain (https://obsnev.es/en/). At the global scale, the Global Observation Research Initiative in Alpine Environments (GLORIA, www.gloria.ac.at; Pauli et al., 2015) is a network monitoring floristic change on mountain summits with a standardized approach. What would complement these highly valuable approaches, is a global long-term monitoring network that covers the full vertical extents of different mountain regions and that allows the detection of species responses to both climate and other human activities.

Here, we present a standardized protocol for monitoring changes in the elevational distribution, abundance and composition of plant biodiversity in mountains as a result of the interaction between climate and human pressures. Importantly, the protocol focuses on large elevation gradients ( $>1700 \mathrm{~m}$ on average; ranging from c. $700 \mathrm{~m}$ to $>4000 \mathrm{~m}$ ), allowing vegetation change to be monitored across a broad range of climates and plant community types. It explicitly contrasts anthropogenically disturbed and (semi-)natural vegetation within sampling sites, thus increasing detection of rapid community changes and providing greater insight into the drivers of change. The protocol has been developed by the Mountain Invasion Research Network (MIREN,www.mountaininvasions.org) (Kueffer et al., 2014), a network initially founded in 2005 to study patterns and processes of non-native plant invasions in mountains and recently expanded to more widely understand the effects of global change on mountain plant biodiversity and the distribution of species. The protocol provides a conceptually intuitive yet comprehensive and standardized way to record and monitor native and non-native species along elevation gradients. The survey has been running in some mountain regions of the world since 2007 (Alexander et al., 2011; Seipel et al., 2012) and continues to be implemented in new regions. In this paper, we summarize the most important findings gained over the time of using this protocol, discuss its strengths and weaknesses and outline opportunities and challenges for future work. To achieve broad reach and long-term maintenance of sites, monitoring protocols must be simple, efficient, and inexpensive. Our intention is to promote the use of the MIREN road survey protocol to monitor biodiversity change in mountains, and to generate global, regional and local insights into how plant species and communities are responding to rapid global change in mountains.

\section{Materials and Methods}

Survey design

The MIREN road survey is conducted by region. In each region, participants select three sample roads that 
extend over a broad elevation gradient, ideally reaching elevations beyond the treeline (for examples, see Figure 1). We define a region as an area in the same biogeographical unit containing similar flora, geology and elevational ranges, usually with distances between roads of less than $150 \mathrm{~km}$ (Figure 2). Selected roads should begin at the bottom of the mountain region, in a valley, at sea level or where no further elevation change occurs, and reach the highest elevation typical for roads in the region. Roads can be gravel or paved but should be open for public vehicle traffic for at least some part of the year. Once roads have been selected, the elevational range of each road is divided into 19 equally wide elevational bands from the lowest to highest possible sampling location, giving a total of 20 sample sites per road located at the splits between elevational bands. Sample sites are determined prior to going into the field and located as precisely as possible using a global positioning system (GPS). At each sample site, three $2 \mathrm{~m} \times 50 \mathrm{~m}$ plots are laid out in the form of a "T": one plot (the top of the "T") is parallel to the road. The other two plots extend end-to-end and perpendicular to the road, starting from the centre of the first plot, with midpoints at $25 \mathrm{~m}$ and $75 \mathrm{~m}$ from the roadside plot (Figure 3). The same plots are resurveyed every five years. If the plot locations have to be changed due to unforeseen circumstances, new sites are placed as near as possible and geolocated.

Plant species surveys

Within each of the three plots at all 20 sample sites along the three roads, observers record all vascular plant species (including both native and non-native species) and visually estimate vegetation cover and record abundance classes of each species. The detailed sampling protocol is provided in Supporting Information S1 and can also be downloaded from the MIREN website (www.mountaininvasions.org). Taxa should be identified to species level using up-to-date local floras. Before being included in the global database, submitted regional species lists undergo taxonomic harmonization to detect synonyms for the same species in different regions, and to correct spelling problems. This procedure is done by the MIREN data managers, using the R-packages "taxize" (Chamberlain \& Szöcs, 2013; Chamberlain et al., 2020) and "WorldFlora" (Kindt, 2020). Firstly, species names are matched with World Flora Online (http://www.worldfloraonline.org), and if not found there, they are searched via the additional databases included in the Taxonomic Names Resolution Service (Boyle et al., 2013). All changes of species names are transmitted to the submitting region for verification or correction, before the dataset enters the global database (Figure 2).

Each taxon should be classified as native or non-native to that region by the participant using local floras and databases. As a general rule, plant species introduced into the country or mountain range after AD 1500 are considered as non-native, although regional deviations are welcome if properly justified. For noteworthy records (e.g. first records or new high/low elevation records of native or non-native species), specimens should be collected outside of the plots (when possible) and placed in a herbarium to facilitate identification and to inform local floras (Walsh \& McDougall, 2018). 
(a)

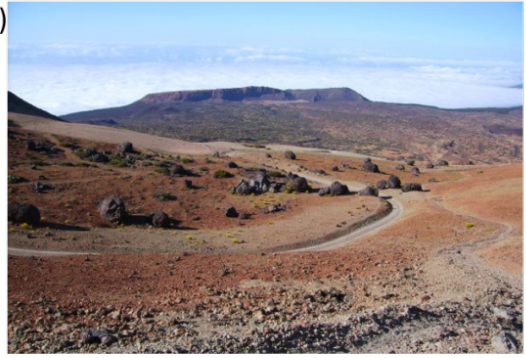

(c)

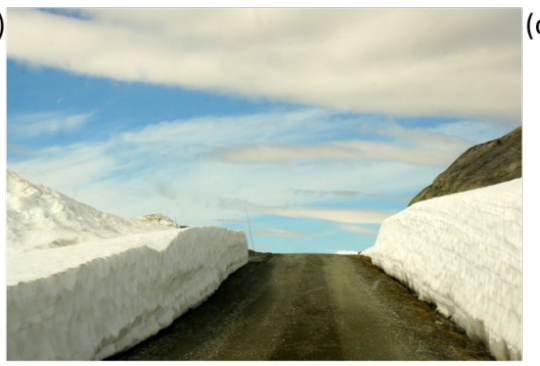

(e)

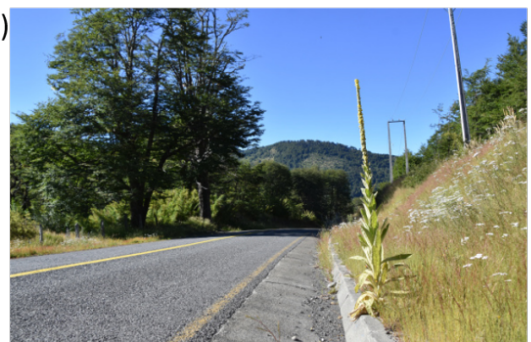

(b)

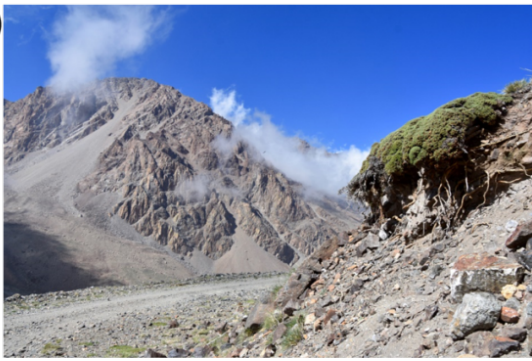

(d)

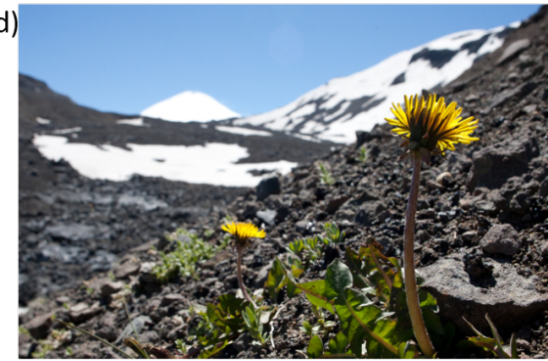

(f)

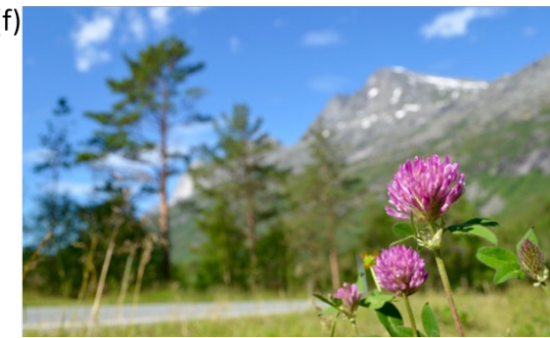

Figure 1: Examples of roads in the landscape (a-c) and key invasive species (d-f) across a range of MIREN regions. (a) Harsh mountain climates (here the Cañadas del Teide on Tenerife (Canary Islands, Spain) have traditionally been seen as an adequate barrier against non-native plant invasion; (b) the direct local impact of roadside disturbance on mountain plants is visible on native Azorella cushion plants along a road in the dry Andes near Mendoza, Argentina; (c) interactive effects of climate and land use, exemplified by dramatic differences in snow cover on versus beside a mountain road in northern Norway; (d) Taraxacum officinale , one of the most widespread non-native plant species along MIREN mountain roads (Seipel et al., 2012), in a sample plot on a volcanic gravel slope in the Argentine Andes; (e) non-native Verbascum thapsus on a roadside in the highly invaded lowlands of the Andes in central Chile; (f) Trifolium pratense in northern Norway, where the species is rapidly moving uphill along mountain roadsides. 


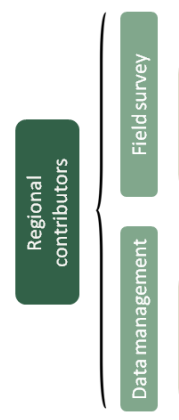

Region selection criteria

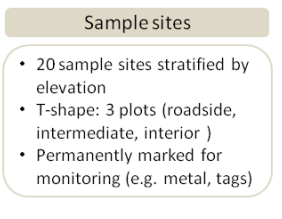

Field measurements

- Cover and abundance of all

vascular species

3 roads $<150 \mathrm{~km}$ distance

Open for vehicular traffic

Contact MIREN prior start

monitoring (e.g. metal, tass)

Bare ground \& litter cover

Region-specific drivers

Flora ID

- All vascular species

identified

Standardized data entry

Data checking \& submission

- Species records (name,

abundance, cover) per plo

Species list (family, author,

native or non-native status)

family/genus/growth form

$\mathrm{New} /$ first records placed in

per region

- Clean \& quality control: species misspellings, synonyms, outliers
- Data submission to MIRE

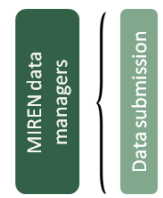

- Metadata of sites \& plots

Data storage \& publication

Data standardization

- Data-sharing agreement

- Data available upon request

- Data publication after 5 yrs.

- Submitted data used for

global taxonomic databases

Data included in the globa

multi-region papers

sent back to contributors for

final correcting

MIREN database

Figure 2. Overview of the workflow from region selection and data collection to inclusion of the data in the global MIREN database. 

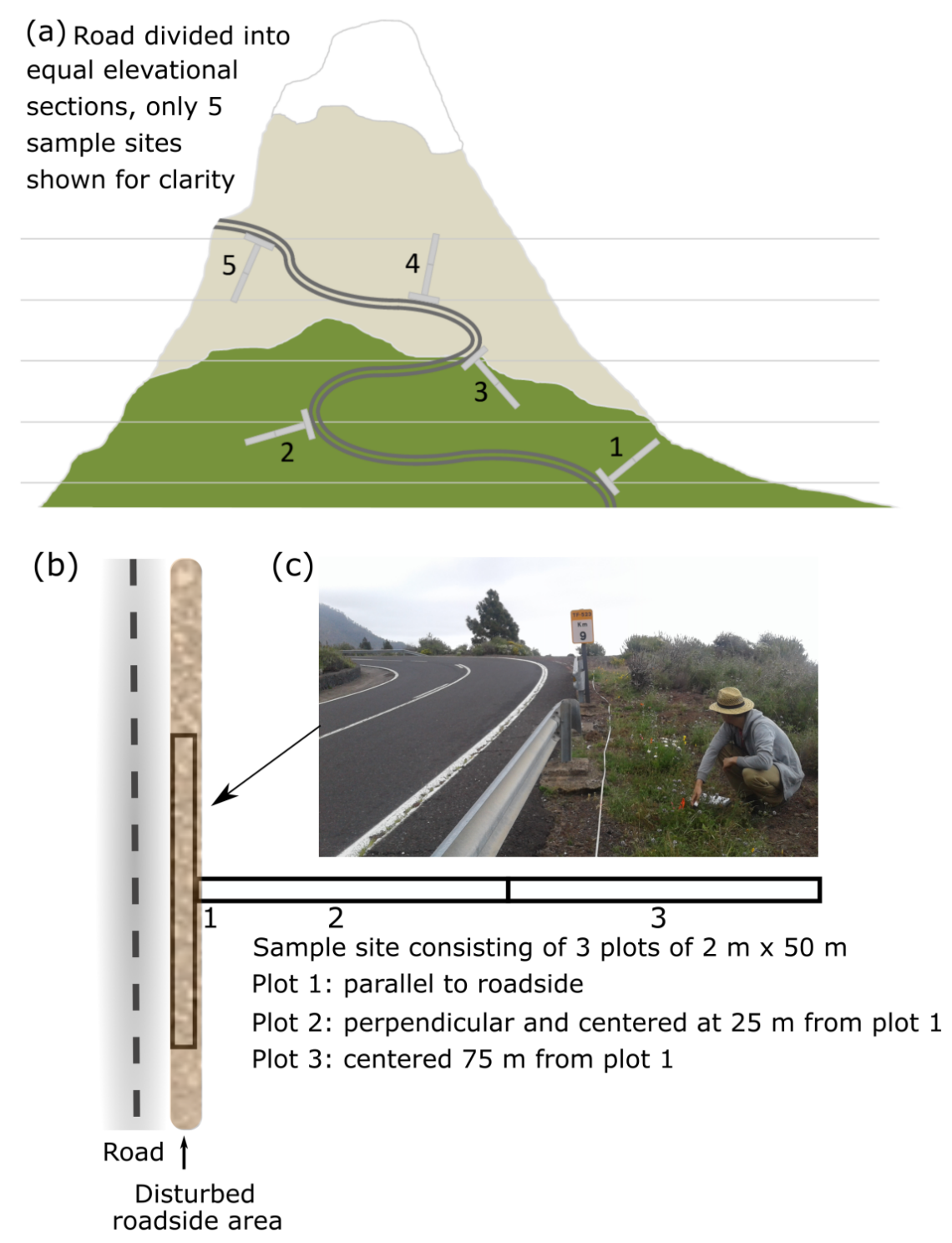

Figure 3: Layout of the MIREN sampling design. (a) Equal elevational distribution of 20 sample sites along a mountain road, of which three are selected in each region; (b) Each sample site consists of 3 plots of $2 \mathrm{~m}$ x $50 \mathrm{~m}$, plot 1 - parallel to the roadside (starting at the first occurrence of roadside vegetation), plot 2 centred $25 \mathrm{~m}$ from the roadside plot, plot 3 - centred $75 \mathrm{~m}$ from the roadside plot; (c) exemplary photograph of monitoring a mountain roadside in Tenerife, Canary Islands, Spain, depicting a survey of plot 1.

\section{Repeated monitoring}

To understand long-term dynamics of redistributions of native and non-native plant species, all regions should strive for regular long-term monitoring, preferably with a periodicity of five years. To facilitate monitoring, all plots should be permanently marked in the field, for instance with magnets or metal tags that can be relocated with a metal detector or coloured sticks or plastic seal security tags in remote areas where their removal is unlikely. In addition, precise sub-meter GPS coordinates should be taken at least once. Photographs should also be taken of each transect to visualize changes over time, document data 
collection and facilitate relocation of plots.

Add-ons to the standardized protocol

In addition to long-term monitoring of plant communities, the MIREN survey design is well suited for additional projects ('add-on' projects) that test more detailed or region-specific questions about the drivers of plant species redistributions. For example, soil temperatures have been recorded with a high temporal resolution for a year or longer in several MIREN regions to document how disturbance along roadsides affects microclimate, including consequences for species redistributions (for the first regional results see Lembrechts et al., 2019). Plant functional traits have additionally been collected for species in Tenerife, Canary Islands, to assess contrasting patterns of intraspecific trait variability of native and non-native species and the change of community mean traits and functional diversity with elevation (Kühn et al., 2020). Another add-on project has focused on soil chemical properties and mycorrhization of native and non-native species in the mountains of Norway (Clavel et al., 2021), and survey plots have also been used to assess the distribution of plant pathogens (Phytophthora species) in Australia (Khaliq, 2019). Once participants begin contributing data to the MIREN global road survey database, they can suggest add-on studies to apply across all regions that go beyond the existing scope of the survey protocol - as long as it is based on a standardized protocol that is fast, simple and low cost to implement by collaborators. To maximize participation and to discuss new proposals, data quality and complementarity, ideas for add-on projects should be developed together with the MIREN steering committee.

\section{Data submission and accessibility}

The MIREN survey design is a robust and standardized field survey protocol that provides data contributors amongst others an opportunity to include regional data in research that addresses globally scaled ecological questions. To be included in MIREN's global road survey database, regional data must be submitted to the MIREN data managers using a standard data format. All data will be made public in the Dryad data repository in the context of paper publications, or at the very latest five years after the survey is undertaken (Figure 2). Any researcher can also request the full MIREN database from MIREN data managers for global analyses. Details regarding data accessibility and publication, the submission of paper proposals and guidelines for co-authorship are given in MIREN's data-sharing agreement (see Supporting Information S2), which can also be downloaded from the MIREN website (www.mountaininvasions.org).

\section{Results}

The standardized protocol for recording plant species communities along mountain roads has been thoroughly tested in the field on all continents except Antarctica (Figure 4). The first survey was carried out in eight regions in 2007 and has been repeated every five years since, resulting in one baseline historical survey (2007) and up to two resurveys (2012 and 2017). The number of regions has increased since 2007, with 18 regions performing the survey by 2018 (Figure 4). The global database currently includes circa 2,700 plots and $>100,000$ observations of $>5,000$ vascular plant species.

One of the most striking findings of the global MIREN surveys to date has been to document the importance of roads in facilitating mountain invasions. Specifically, we have found that non-native species richness in roadsides decreases with increasing elevation, but generally peaks in the lower third of the elevation gradient (Alexander et al., 2011). Moreover, the vast majority of non-native species found at high elevation are also present at low elevation, with only $2.3 \%$ of high-elevation non-native species being specifically adapted to alpine environments (Alexander et al., 2016). These findings indicate that non-native species are first introduced and become established at low elevation sites, following this they spread to higher elevations (Alexander et al., 2011). At higher elevation sites, non-native species generally become increasingly filtered out by environmental pressures, so fewer warm-adapted perennials reach higher elevations (McDougall et al., 2018). We have also revealed that the number of non-native species declines with increasing distance from the road (Seipel et al., 2012; Haider et al., 2018), indicating that the native plant community serves as a second environmental filter that selects for more shade- and moisture-tolerant perennials (McDougall et al., 2018). In addition to non-native species, the MIREN surveys have shown that native species also use roads 
as corridors (Lembrechts et al., 2017). Interestingly, Lembrechts et al. (2017) found that occurrence optima are higher in roadside habitats than faraway habitats, and moreover that some alpine species have shifted their ranges downwards due to altered abiotic conditions and competitive release in roadside habitats (see also e.g. Lenoir et al., 2010).

Globally, the MIREN surveys have demonstrated that native plant species richness does not follow a consistent pattern in non-roadside (semi-)natural habitat along elevation gradients, suggesting the existence of additional region-specific mechanisms, such as biome, vegetation type and human activity. These mechanisms are now the subject of further study. In contrast, a clearer elevation signal is present on roadside plots, with total species richness peaking at mid-elevations in most regions (Haider et al., 2018). Further, we have observed a reduction in community dissimilarity (beta-diversity) along roadsides relative to more distant plots, which is amplified by the arrival of non-native species along mountain roadsides homogenizing plant community composition (Haider et al., 2018). The MIREN surveys have also provided insight into the vulnerability of habitats regionally (Pollnac et al., 2012), the genetic background of successful invasions (Haider et al., 2012) and the impact and management of local invasions (McDougall et al., 2011a). For example, in the Greater Yellowstone Ecosystem in the United States, we found that non-native species emergence varies with elevation and habitat type, which provided land managers valuable information for mitigating biological invasions (Pollnac et al., 2012). Moreover, in the dry Mediterranean Andes in Argentina, which are characterized by treeless vegetation, the survey demonstrated how non-native plant species can successfully spread from the roadside into natural vegetation at low and intermediate elevations, thus highlighting the susceptibility of these types of ecosystems to invasion (Aschero et al., 2017). By contrast, the alpine vegetation of northern Norway has been shown to be more vulnerable to invasion than its low elevation counterpart, indicating that vegetation structure plays an important role in community invasibility (Lembrechts et al., 2014). Finally, the MIREN surveys have already generated information about regional floras. An excellent example is the discovery of a new species of Poaceae during MIREN monitoring in Kosciuszko National Park, Australia - this species was named after the network: Poa mireniana (Walsh \& McDougall, 2018).

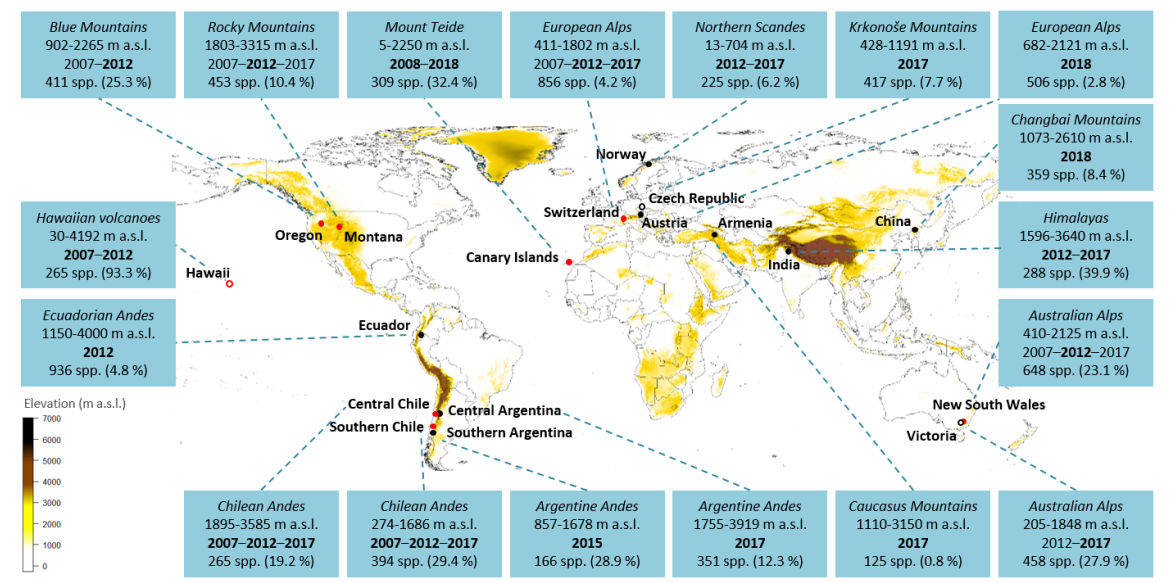

Figure 4: Regions worldwide participating in the vegetation survey along mountain roads according to the standardized protocol of the Mountain Invasion Research Network (MIREN). Red symbols indicate the founding regions from the first survey in 2007. In regions with unfilled symbols, only roadside plots, but not intermediate and interior plots in natural vegetation were sampled. For each region, the name of the mountain range, the sampled elevation gradient and the year(s) of sampling are given. Years in bold indicate that both native and non-native species were recorded, while in years with normal font only non-native species were recorded. Note that some regions did not follow the 5-year sampling frequency. In the last row, the total number of species and in parentheses the proportion of non-native species are summarized.

\section{Discussion}




\section{Strengths of the protocol}

The MIREN road survey protocol is unique for its focus on two critical co-occurring global change drivers on biodiversity and species redistributions in mountains: climate change and road construction (Figure 5). Road construction represents one of the most prominent and increasing land-use changes in many remote regions (Meijer et al., 2018), leading to physical disturbance, dispersal corridors and vectors for plant species (Gelbard \& Belnap, 2003). Coupled with this, elevation gradients are good proxies for temperature and can be used as space-for-time model systems for simulating climate change-induced temperature increase, where low elevation systems to a certain extent represent future scenarios for higher elevations in a warming climate (Blois et al., 2013; Lembrechts et al., 2017). Given this, combining elevation-based climate gradients with road effects allows researchers to disentangle the interactive effects of climate and road construction as an example of human land-use change - on biodiversity, including their relative importance as drivers of species redistributions. Indeed, it is along clear linear dispersal pathways like roads that changes in species distributions - and especially those of non-native species - become apparent (Lembrechts et al., 2017). This is particularly relevant when considering the repeated survey approach of the MIREN design, which makes it possible to study the temporal dynamics of plant species distributions in response to natural (e.g. succession after natural disturbances, such as fire), as well as anthropogenic disturbances (e.g. land-use changes, such as increasing urbanization or domestic grazing, or the introduction of non-native species).

A final advantage is that along each road, sites are selected at predetermined elevations and capture all habitats found along an elevation gradient, equally covering all elevational belts. The protocol provides a methodological standardization that is straightforward to replicate globally and yet still yields sufficient explanatory power for regional case studies due to due to its relationship to the elevation gradient and its within-region replication (i.e. sampling along three mountain roads in each region; e.g. Arévalo et al., 2010; Pollnac et al., 2012). In doing so, the protocol remains simple, for example with plots close to roads remaining easy to reach, and thus applicable in many mountain regions even when fieldwork sites need to be easily accessible. This provides another strength of the protocol: it can be repeated in many places, so that general patterns at the global scale can be detected through multi-region replication (Alexander et al., 2011; Seipel et al., 2012; Lembrechts et al., 2017). In summary, data collected within the MIREN survey framework can be useful for regional and global studies in a large variety of fields, ranging from classical biogeography and community ecology to ecological modelling and global change research. 

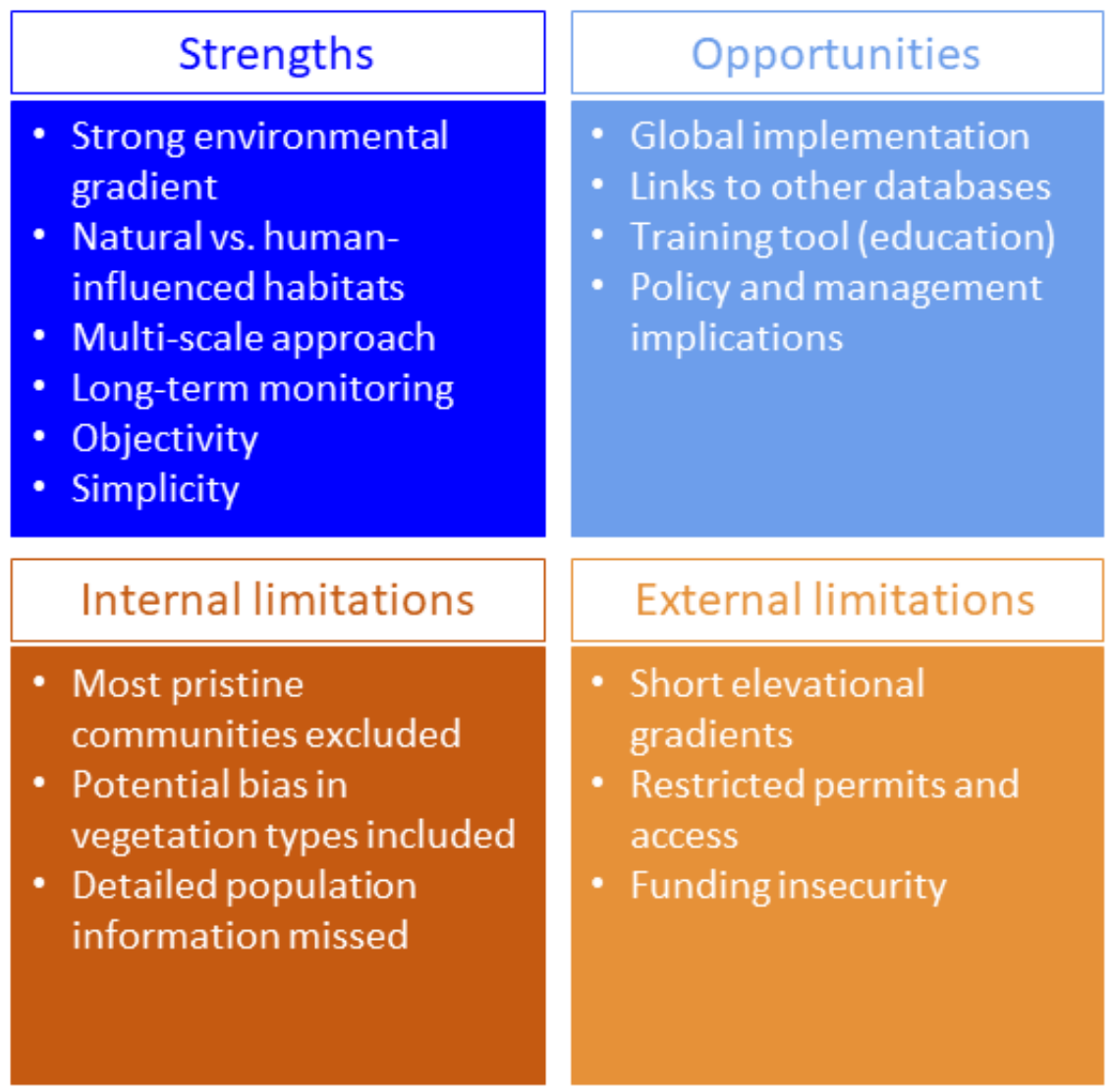

Figure 5: Summary of the strengths and opportunities of the MIREN road survey protocol as well as limitations of the protocol itself and those resulting from external circumstances.

Limitations of the protocol

The focus of the protocol on mountain roads provides excellent opportunities to disentangle the effects of climate and road construction on plant species and community redistributions. However, the protocol also has three important limitations (Figure 5).

First, the protocol excludes the most pristine environments that exist far from roads and at elevations above where roads reach, so does not monitor mountain biodiversity as a whole. As such, the protocol is a complement to the GLORIA protocol, which focuses on long-term climate change-related vegetation shifts on undisturbed mountain summits (Pauli et al., 2015). Nevertheless, one regional study has shown that, at least in northern Scandinavia, the effect of roads on mountain plant diversity disappears beyond $25 \mathrm{~m}$ from the roadside (Lembrechts et al., 2014), suggesting that the vegetation surveyed in the MIREN survey plot furthest from the roadside (Figure 3b; 50-100 m distance) may indeed be representative of regional biodiversity. Yet, using these data beyond the $100 \mathrm{~m}$ reach of the sample site could bring issues for some applications, such as spatial modelling, where extrapolations for locations away from the road will suffer from increased uncertainty (Kadmon et al., 2004). Coupled to this, the restriction of the protocol to mountain roads means that, depending on the heterogeneity of the landscape, not all habitat types are necessarily covered relative to their distribution in the ecosystem. Plot locations may be biased towards valleys and less steep terrain if road construction favours such areas. Additionally, while roads represent the most prominent dispersal pathway present in mountains, they are not the only one (e.g. rivers, mountain trails, powerline cuttings, cable cars; Foxcroft et al., 2019). However, the protocol could be easily adapted for other pathways 
(as done for trails (Liedtke et al., 2020) and rivers (Vorstenbosch et al., 2020)), and we suggest that this would be of particular interest in regions with sparse roads and/or where most of the common non-native species are wind or water dispersed.

Second, MIREN adopts a discrete temporal and spatial sampling approach. Specifically, since the protocol focuses on community dynamics and large-scale patterns it lacks the spatio-temporal resolution to monitor individual species and populations over time. The relatively low spatial sampling intensity (i.e. few plots for each elevational belt) and sometimes large distances between elevational increments (e.g. on average c. $75 \mathrm{~m}$ steps across current MIREN regions) can limit understanding of local processes, while also biasing sampling against rarer plant species or habitats. Furthermore, while repeated surveys facilitate investigation of species range dynamics under global change, the complete design does not explicitly consider dispersal dynamics (e.g. through seed rain or seed bank sampling, or seed tracking), instead assessing such dynamics indirectly through repeated snapshots of plant community composition.

Third, the standard protocol emphasises simplicity to be as inclusive as possible and to keep resource use to a minimum. The approach thus focuses chiefly on plant community composition and coarse estimates of species abundance (see Supporting Information S1). Other important variables such as biomass, functional traits, community 3D-structure, species interactions and other abiotic and biotic variables thus require additional sampling effort. For the same reason, the protocol is limited to vascular plants, excluding bryophytes and other taxonomic groups of potential interest.

Finally, the assumption that elevation can serve as a proxy for climate is of particular relevance here. Testing how the elevation gradient correlates with fine-grained climatic gradients requires validation using high-resolution climate data produced either using in-situmeasurements or downscaling of climate models (Lembrechts et al., 2019). We therefore recommend participants to include at least one add-on study that deploys temperature data loggers to allow linking of vegetation patterns with microclimatic gradients (Lembrechts et al., 2019) - although this would already add cost.

\section{External limitations}

Application of the MIREN road survey protocol might be hindered in some regions, most obviously due to the lack of roads spanning sufficiently large elevation gradients. Additionally, local land ownership, safety issues or administrative complexities may complicate establishment and monitoring, for example on private land or in protected areas (Figure 5). Such issues might be of particular relevance in the MIREN survey design, as MIREN strives to cover a large elevation gradient spanning multiple vegetation zones. At the same time, the proximity of survey plots to roads increases the risk of damage over time (e.g. through road widening, mowing, pesticide use, expanding urbanization or occasional vandalism). The simplicity of the plot set-up nevertheless greatly reduces the impact of such damage or vandalism in the long term.

Long-term monitoring itself comes at a risk of funding insecurities, as the timeframe of 5-year intervals is beyond what is covered by most grants. Even though maintaining the observational sites themselves comes at virtually no financial cost, the monitoring involves considerable input of field labour, for which costs will vary between regions (Figure 5).

\section{Opportunities}

Many drivers of global change act rapidly and interactively, and intensify over time, so assessing their impact on global biodiversity urgently requires comparable data collected on a truly global scale. The MIREN road survey protocol has already demonstrated its potential to explain crucial patterns in native and non-native species redistributions along mountain roads, but there are a range of further applications that can be explored. For example, due to its simplicity the protocol can readily be implemented in many more mountain ranges and regions. Increasing the number of participating regions, all with their unique combination of climatic conditions and anthropogenic pressures, would further increase the potential to draw general conclusions about the interacting effects of climate change and roads as anthropogenic disturbance on mountain plant communities (Guo et al., 2018). This is particularly important for regions currently under- 
represented by the existing MIREN survey sites (Figure 4), such as Africa, Eastern Asia and central America, regions for which long-term biodiversity data are often lacking (Maestre \& Eisenhauer, 2019). Despite these spatial gaps, MIREN has already more than doubled in size on its road to becoming a global-scale network since it was first established in eight regions. New participants would thus be able to place their region into a much larger spatio-temporal picture and, as time passes, get an increasingly strong grasp of how species distributions are changing dynamically, regionally and across the world.

With its potential to answer important local questions, and feed into the growing multi-region database, we hope that the MIREN road survey protocol will become the protocol of choice for those interested in native and non-native plant biodiversity dynamics in mountain regions. At the local scale, it can provide good baseline data on biodiversity changes along elevation gradients in disturbed regions, with opportunities to inform management decisions (McDougall et al., 2011a). For example, it can inform policy makers on some of the impacts of urban expansion and new infrastructure projects in mountains, as well as identify new nonnative species before they become problematic. The protocol can also provide essential biodiversity variables for global monitoring efforts (Jetz et al., 2019), since it provides insight into species abundance change over space and time and can further enrich the mountain biodiversity data provided on the online data portal of the Global Mountain Biodiversity Assessment (GMBA). In doing so, it has the capacity to inform global biodiversity policy initiatives, such as the Intergovernmental Science-Policy Platform on Biodiversity and Ecosystem Services (IPBES).

Further opportunities include add-ons and expansions to the protocol design, for example to measure microclimate (Lembrechts et al., 2019), dispersal dynamics (e.g. with seed traps), soil biodiversity (e.g. analyses of the soil microbiome or mycorrhizal colonization of roots) or plant-animal interactions (e.g. pollinator records, herbivore abundance). Collecting such data would be important not only in isolation, but also for helping to create explicit links between descriptive and predictive species distribution models, both at local and global scales. Such efforts could even facilitate modelling of (changes in) the distributions and habitat occupation of mountain plant species, for instance by coupling georeferenced long-term survey plots with high-resolution remotely sensed and modelled environmental data (Randin et al., 2020). The survey approach can similarly be expanded by adapting it for use along other linear introduction pathways for nonnative species, such as rivers or hiking trails, or by connecting it with other standardized global biodiversity surveys and assessments, such as GLORIA (Pauli et al., 2015), sPlot (Bruelheide et al., 2019), the Global Inventory of Floras and Traits (GIFT; Weigelt et al., 2020), the Global Naturalized Alien Flora (GloNAF) database (van Kleunen et al., 2015) and the BioTIME database (Dornelas et al., 2018). Finally, the protocol has already shown to have great potential for teaching, for instance by training undergraduate and graduate students in vegetation sampling, while also having relevance for local policy and management, for example as demonstration sites (Figure 5).

\section{Conclusions}

The MIREN road survey protocol started in 2007 with a specific purpose - to monitor non-native plant species invasions along mountain roads - but has since then proven to be well-suited for an increasing number of questions related to species redistributions in the fields of biogeography, ecology and conservation biology. The protocol is low-tech, straightforward and standardized, and can therefore be implemented immediately to fill global gaps in biodiversity data, especially in areas that are traditionally underrepresented in global biodiversity studies (Nuñez et al., 2019) or in regions with scarce or fluctuating government support for scientific research. In short, this on-the-ground, multi-regional, simple yet effective monitoring scheme is a perfect example of 'Think globally, measure locally', and has clear capacity to bring together ecologists from around the world to generate an even more complete picture of ongoing species redistributions in mountains. We invite you all to join us!

\section{Acknowledgements}

We gratefully acknowledge the immense effort and time that numerous professionals, field assistants, and students have contributed to the collection of these data. SH and ARB gratefully acknowledge the support of 
iDiv funded by the German Research Foundation (DFG-FZT 118, 202548816). JJL received a postdoctoral fellowship from the Research Foundation Flanders (FWO, grant nr. 12P1819N), and OG received a postdoctoral research fellowship through the Afromontane Research Unit, University of the Free State. The work from JJL, JC and IN is supported by a research grant from the FWO (grant nr. G018919N). KLS thanks funding received from PICT 2015-2072 and PIP 2014-0758. LAC and AP acknowledge support from FONDECYT 1171005, 1180205 and CONICYT PIA CCTE AFB170008. VS was supported by SENESCYT-Ecuador, Instituto de Ecologia y Biodiversidad (IEB) and Laboratorio de Ecologia, Biogeografia y Sistematica (ECOBIOSIS) de la Universidad de Concepcion, Laboratorio de Invasiones Biologicas (LIB) de la Universidad de Concepcion, Herbario QCA and QCNE-Ecuador, Missouri Botanical Garden, and CONICYT (PFB-023). MV was supported by a research grant from the BiodivClim Call 2019 (grant nr. TACR SS70010001) and together with JM by long-term research development project RVO 67985939 from the Czech Academy of Sciences. FE, BL and TV acknowledge funding by the Austrian Science Foundation FWF (grant I 3757-B29). PK acknowledges support from the Swedish Research Council (Vetenskapsradet) (project grant 2015-04214). BN was supported by the US Forest Service and direct mentorship from C. Parks. Fieldwork in the Northern Scandes is achieved using INTERACT Transnational Access funding. AM and VA were supported by the Universidad Nacional de Cuyo (SIIP 2019 UNCUYO) and the Rufford Foundation. JMA received funding from the European Commission Horizon 2020 research and innovation programme under grant agreement 678841. We also thank the Fondation Herbette, University of Lausanne, for financial support to JMA for the workshop "Distributed ecological observatories and long-term monitoring of mountain biodiversity" held in September 2019 that lead up to this paper.

\section{Authors' contribution}

This paper builds on the protocol as designed originally by the Mountain Invasion Research Network (MIREN) by SH, KM, AP, JMA, LJR, JRA, CD, HD, PE, GJ, CK and BN. The idea for the paper and further fine-tuning of the protocol stems from a MIREN workshop in 2019, attended by SH, KM, AP, JMA, AB, IR, LJR, AnB, ARB, CC, BE, AG, AH, TTH, PK, CK, DP, EFL, JL, RVC, SR, VV, TW, REMW, SZ, and TS. SH, JJL and TS led the writing of the manuscript, with contributions by the MIREN steering committee (KM, AP, JMA, AB, LAC, IR, LJR). All authors contributed critically to the drafts - based on their experience in applying the protocol in their regions - and gave final approval for publication.

\section{Data availability}

Data collected according to the MIREN road survey protocol will be published in the context of paper publications or five years after data collection. Details are governed in the current version of the MIREN datasharing agreement which is available on the network's website (www.mountaininvasions.org) and provided as supplementary material to this manuscript.

\section{Supporting Information}

Supporting Information S1: MIREN road survey protocol

Supporting Information S2: MIREN Data-sharing agreement

\section{References}

Alexander, J.M., Chalmandrier, L., Lenoir, J., Burgess, T.I., Essl, F., Haider, S., Kueffer, C., McDougall, K., Milbau, A., Nunez, M.A., Pauchard, A., Rabitsch, W., Rew, L.J., Sanders, N.J. \& Pellissier, L. (2018). Lags in the response of mountain plant communities to climate change. Global Change Biology, 24, 563-579. https://doi.org/10.1111/gcb.13976.

Alexander, J.M., Kueffer, C., Daehler, C.C., Edwards, P.J., Pauchard, A., Seipel, T. \& MIREN Consortium (2011). Assembly of nonnative floras along elevational gradients explained by directional ecological filtering. Proceedings of the National Academy of Sciences of the United States of America, 108, 656-661. https://doi.org/10.1073/pnas.1013136108. 
Alexander, J.M., Lembrechts, J.J., Cavieres, L.A., Daehler, C., Haider, S., Kueffer, C., Liu, G., McDougall, K., Milbau, A., Pauchard, A., Rew, L.J. \& Seipel, T. (2016). Plant invasions into mountains and alpine ecosystems: current status and future challenges. Alpine Botany,126, 89-103. https://doi.org/10.1007/s00035-016-0172-8.

Ansong, M. \& Pickering, C. (2013). Are weeds hitchhiking a ride on your car? A systematic review of seed dispersal on cars. PLoS ONE,8, e80275. https://doi.org/10.1371/journal.pone.0080275.

Arevalo, J.R., Otto, R., Escudero, C., Fernandez Lugo, S., Arteaga, M.A., Delgado, J.D. \& Fernandez Palacios, J.M. (2010). Do anthropogenic corridors homogenize plant communities at a local scale? A case studied in Tenerife (Canary Islands). Plant Ecology, 209, 23-35. https://doi.org/10.1007/s11258-009-9716-y.

Aschero, V., Barros, A., Bonjour, L.J. \& Perez Sosa, M.C. (2017). Invasiones de plantas en caminos vehiculares de montana de los Andes centrales: sobre patas o sobre ruedas? Boletin de la Sociedad Argentina de Botanica, 52 (Supl), 97.

Averett, J.P., McCune, B., Parks, C.G., Naylor, B.J., DelCurto, T. \& Mata-Gonzalez, R. (2016). Non-native plant invasion along elevation and canopy closure gradients in a middle Rocky Mountain ecosystem.PLoS ONE, 11, e0147826. https://doi.org/10.1371/journal.pone.0147826.

Barros, A., Aschero, V., Mazzolari, A., Cavieres, L.A. \& Pickering, C.M. (2020). Going off trails: How dispersed visitor use affects alpine vegetation. Journal of Environmental Management, 267,110546. https://doi.org/10.1016/j.jenvman.2020.110546.

Blois, J.L., Williams, J.W., Fitzpatrick, M.C., Jackson, S.T. \& Ferrier, S. (2013). Space can substitute for time in predicting climate-change effects on biodiversity. Proceedings of the National Academy of Sciences of the United States of America,110, 9374-9379. https://doi.org/10.1073/pnas.1220228110.

Boyle, B., Hopkins, N., Lu, Z., Raygoza Garay, J.A., Mozzherin, D., Rees, T., Matasci, N., Narro, M.L., Piel, W.H., McKay, S.J., Lowry, S., Freeland, C., Peet, R.K. \& Enquist, B.J. (2013). The taxonomic name resolution service: an online tool for automated standardization of plant names. BMC Bioinformatics, 14, 16. https://doi.org/10.1186/1471-2105-14-16.

Bruelheide, H., Dengler, J., Jimenez-Alfaro, B., Purschke, O., Hennekens, S.M., Chytry, M., Pillar, V.D., Jansen, F., Kattge, J., Sandel, B., Aubin, I., Biurrun, I., Field, R., Haider, S., Jandt, U., Lenoir, J., Peet, R.K., Peyre, G., Sabatini, F.M., Schmidt, M., Schrodt, F., Winter, M., Aćić, S., Agrillo, E., Alvarez, M., Ambarlı, D., Angelini, P., Apostolova, I., Arfin Khan, M.A.S., Arnst, E., Attorre, F., Baraloto, C., Beckmann, M., Berg, C., Bergeron, Y., Bergmeier, E., Bjorkman, A.D., Bondareva, V., Borchardt, P., Botta-Dukát, Z., Boyle, B., Breen, A., Brisse, H., Byun, C., Cabido, M.R., Casella, L., Cayuela, L., Černý, T., Chepinoga, V., Csiky, J., Curran, M., Ćušterevska, R., Dajić Stevanović, Z., De Bie, E., de Ruffray, P., De Sanctis, M., Dimopoulos, P., Dressler, S., Ejrnæs, R., El-Sheikh, M.A.E.-R.M., Enquist, B., Ewald, J., Fagúndez, J., Finckh, M., Font, X., Forey, E., Fotiadis, G., García-Mijangos, I., de Gasper, A.L., Golub, V., Gutierrez, A.G., Hatim, M.Z., He, T., Higuchi, P., Holubová, D., Hölzel, N., Homeier, J., Indreica, A., Işık Gürsoy, D., Jansen, S., Janssen, J., Jedrzejek, B., Jiroušek, M., Jürgens, N., Kącki, Z., Kavgacı, A., Kearsley, E., Kessler, M., Knollová, I., Kolomiychuk, V., Korolyuk, A., Kozhevnikova, M., Kozub, Ł., Krstonošić, D., Kühl, H., Kühn, I., Kuzemko, A., Küzmič, F., Landucci, F., Lee, M.T., Levesley, A., Li, C.-F., Liu, H., Lopez-Gonzalez, G., Lysenko, T., Macanović, A., Mahdavi, P., Manning, P., Marcenò, C., Martynenko, V., Mencuccini, M., Minden, V., Moeslund, J.E., Moretti, M., Müller, J.V., Munzinger, J., Niinemets, Ü., Nobis, M., Noroozi, J., Nowak, A., Onyshchenko, V., Overbeck, G.E., Ozinga, W.A., Pauchard, A., Pedashenko, H., Peñuelas, J., Pérez-Haase, A., Peterka, T., Petř́k, P., Phillips, O.L., Prokhorov, V., Rašomavičius, V., Revermann, R., Rodwell, J., Ruprecht, E., Rūsiņa, S., Samimi, C., Schaminée, J.H.J., Schmiedel, U., Šibík, J., Šilc, U., Škvorc, Ž., Smyth, A., Sop, T., Sopotlieva, D., Sparrow, B., Stančić, Z., Svenning, J.-C., Swacha, G., Tang, Z., Tsiripidis, I., Turtureanu, P.D., Uğurlu, E., Uogintas, D., Valachovič, M., Vanselow, K.A., Vashenyak, Y., Vassilev, K., Vélez-Martin, E., Venanzoni, R., Vibrans, A.C., Violle, C., Virtanen, R., von Wehrden, H., Wagner, V., Walker, D.A., Wana, D., Weiher, E., Wesche, K., Whitfeld, T., Willner, 
W., Wiser, S., Wohlgemuth, T., Yamalov, S., Zizka, G. \& Zverev, A. (2019). sPlot - A new tool for global vegetation analyses. Journal of Vegetation Science, 30, 161-186. https://doi.org/10.1111/jvs.12710.

Chamberlain, S., Szoecs, E., Foster, Z., Arendsee, Z., Boettiger, C., Ram, K., Bartomeus, I., Baumgartner, J., O'Donnell, J., Oksanen, J., Tzovaras, B.G., Marchand, P., Tran, V., Salmon, M., Li, G. \& Grenié, M. (2020). taxize: Taxonomic information from around the web. R package version 0.9.98. https://github.com/ropensci/taxize

Chamberlain, S.A. \& Szöcs, E. (2013). taxize: taxonomic search and retrieval in R [version 2; peer review: 3 approved].F1000Research, 2, 191. https://doi.org/10.12688/f1000research.2-191.v2.

Clavel, J., Lembrechts, J., Alexander, J., Haider, S., Lenoir, J., Milbau, A., Nuñez, M.A., Pauchard, A., Nijs, I. \& Verbruggen, E. (2021). The role of arbuscular mycorrhizal fungi in nonnative plant invasion along mountain roads. New Phytologist, n/a. https://doi.org/10.1111/nph.16954.

Cóbar-Carranza, A.J., García, R.A., Pauchard, A. \& Peña, E. (2014). Effect of Pinus contorta invasion on forest fuel properties and its potential implications on the fire regime of Araucaria araucana and Nothofagus antarctica forests. Biological Invasions, 16, 2273-2291. https://doi.org/10.1007/s10530-014-0663-8.

Daehler, C.C. (2005). Upper-montane plant invasions in the Hawaiian Islands: patterns and opportunities. Perspectives in Plant Ecology, Evolution and Systematics, 7, 203-216. https://doi.org/10.1016/j.ppees.2005.08.002.

Dainese, M., Aikio, S., Hulme, P.E., Bertolli, A., Prosser, F. \& Marini, L. (2017). Human disturbance and upward expansion of plants in a warming climate. Nature Climate Change, 7, 577-580. https://doi.org/10.1038/nclimate3337.

Debarbieux, B., Oiry Varacca, M., Rudaz, G., Maselli, D., Kohler, T. \& Jurek, M. (2014). Tourism in mountain regions: Hopes, fears and realities. Sustainable Mountain Development Series , pp. 108. UNIGE, CDE, SDC, Geneva, Switzerland.

Dickson, J.H., Rodriguez, J.C. \& Machado, A. (1987). Invading plants at high altitudes on Tenerife especially in the Teide National Park.Botanical Journal of the Linnean Society, 95, 155-179.

Dornelas, M., Antão, L.H., Moyes, F., Bates, A.E., Magurran, A.E., Adam, D., Akhmetzhanova, A.A., Appeltans, W., Arcos, J.M., Arnold, H., Ayyappan, N., Badihi, G., Baird, A.H., Barbosa, M., Barreto, T.E., Bässler, C., Bellgrove, A., Belmaker, J., Benedetti-Cecchi, L., Bett, B.J., Bjorkman, A.D., Błażewicz, M., Blowes, S.A., Bloch, C.P., Bonebrake, T.C., Boyd, S., Bradford, M., Brooks, A.J., Brown, J.H., Bruelheide, H., Budy, P., Carvalho, F., Castañeda-Moya, E., Chen, C.A., Chamblee, J.F., Chase, T.J., Siegwart Collier, L., Collinge, S.K., Condit, R., Cooper, E.J., Cornelissen, J.H.C., Cotano, U., Kyle Crow, S., Damasceno, G., Davies, C.H., Davis, R.A., Day, F.P., Degraer, S., Doherty, T.S., Dunn, T.E., Durigan, G., Duffy, J.E., Edelist, D., Edgar, G.J., Elahi, R., Elmendorf, S.C., Enemar, A., Ernest, S.K.M., Escribano, R., Estiarte, M., Evans, B.S., Fan, T.-Y., Turini Farah, F., Loureiro Fernandes, L., Farneda, F.Z., Fidelis, A., Fitt, R., Fosaa, A.M., Daher Correa Franco, G.A., Frank, G.E., Fraser, W.R., García, H., Cazzolla Gatti, R., Givan, O., Gorgone-Barbosa, E., Gould, W.A., Gries, C., Grossman, G.D., Gutierréz, J.R., Hale, S., Harmon, M.E., Harte, J., Haskins, G., Henshaw, D.L., Hermanutz, L., Hidalgo, P., Higuchi, P., Hoey, A., Van Hoey, G., Hofgaard, A., Holeck, K., Hollister, R.D., Holmes, R., Hoogenboom, M., Hsieh, C.-h., Hubbell, S.P., Huettmann, F., Huffard, C.L., Hurlbert, A.H., Macedo Ivanauskas, N., Janík, D., Jandt, U., Jażdżewska, A., Johannessen, T., Johnstone, J., Jones, J., Jones, F.A.M., Kang, J., Kartawijaya, T., Keeley, E.C., Kelt, D.A., Kinnear, R., Klanderud, K., Knutsen, H., Koenig, C.C., Kortz, A.R., Král, K., Kuhnz, L.A., Kuo, C.-Y., Kushner, D.J., Laguionie-Marchais, C., Lancaster, L.T., Min Lee, C., Lefcheck, J.S., Lévesque, E., Lightfoot, D., Lloret, F., Lloyd, J.D., López-Baucells, A., Louzao, M., Madin, J.S., Magnússon, B., Malamud, S., Matthews, I., McFarland, K.P., McGill, B., McKnight, D., McLarney, W.O., Meador, J., Meserve, P.L., Metcalfe, D.J., Meyer, C.F.J., Michelsen, A., Milchakova, N., Moens, T., Moland, E., Moore, J., Mathias Moreira, C., Müller, J., Murphy, G., Myers-Smith, I.H., Myster, R.W., Naumov, A., Neat, F., Nelson, J.A., Paul Nelson, M., Newton, S.F., Norden, N., Oliver, J.C., Olsen, E.M., Onipchenko, V.G., Pabis, K., Pabst, 
R.J., Paquette, A., Pardede, S., Paterson, D.M., Pélissier, R., Peñuelas, J., Pérez-Matus, A., Pizarro, O., Pomati, F., Post, E., Prins, H.H.T., Priscu, J.C., Provoost, P., Prudic, K.L., Pulliainen, E., Ramesh, B.R., Mendivil Ramos, O., Rassweiler, A., Rebelo, J.E., Reed, D.C., Reich, P.B., Remillard, S.M., Richardson, A.J., Richardson, J.P., van Rijn, I., Rocha, R., Rivera-Monroy, V.H., Rixen, C., Robinson, K.P., Ribeiro Rodrigues, R., de Cerqueira Rossa-Feres, D., Rudstam, L., Ruhl, H., Ruz, C.S., Sampaio, E.M., Rybicki, N., Rypel, A., Sal, S., Salgado, B., Santos, F.A.M., Savassi-Coutinho, A.P., Scanga, S., Schmidt, J., Schooley, R., Setiawan, F., Shao, K.-T., Shaver, G.R., Sherman, S., Sherry, T.W., Siciński, J., Sievers, C., da Silva, A.C., Rodrigues da Silva, F., Silveira, F.L., Slingsby, J., Smart, T., Snell, S.J., Soudzilovskaia, N.A., Souza, G.B.G., Maluf Souza, F., Castro Souza, V., Stallings, C.D., Stanforth, R., Stanley, E.H., Mauro Sterza, J., Stevens, M., Stuart-Smith, R., Rondon Suarez, Y., Supp, S., Yoshio Tamashiro, J., Tarigan, S., Thiede, G.P., Thorn, S., Tolvanen, A., Teresa Zugliani Toniato, M., Totland, Ø., Twilley, R.R., Vaitkus, G., Valdivia, N., Vallejo, M.I., Valone, T.J., Van Colen, C., Vanaverbeke, J., Venturoli, F., Verheye, H.M., Vianna, M., Vieira, R.P., Vrška, T., Quang Vu, C., Van Vu, L., Waide, R.B., Waldock, C., Watts, D., Webb, S., Wesołowski, T., White, E.P., Widdicombe, C.E., Wilgers, D., Williams, R., Williams, S.B., Williamson, M., Willig, M.R., Willis, T.J., Wipf, S., Woods, K.D., Woehler, E.J., Zawada, K. \& Zettler, M.L. (2018). BioTIME: A database of biodiversity time series for the Anthropocene. Global Ecology and Biogeography, 27, 760-786. https://doi.org/10.1111/geb.12729.

Dullinger, S., Gattringer, A., Thuiller, W., Moser, D., Zimmermann, N.E., Guisan, A., Willner, W., Plutzar, C., Leitner, M., Mang, T., Caccianiga, M., Dirnbock, T., Ertl, S., Fischer, A., Lenoir, J., Svenning, J.C., Psomas, A., Schmatz, D.R., Silc, U., Vittoz, P. \& Hulber, K. (2012). Extinction debt of high-mountain plants under twenty-first-century climate change. Nature Climate Change,2, 619-622. https://doi.org/10.1038/nclimate1514.

Elsen, P.R., Monahan, W.B. \& Merenlender, A.M. (2020). Topography and human pressure in mountain ranges alter expected species responses to climate change. Nature Communications, 11, 1974. https://doi.org/10.1038/s41467-020-15881-x.

Foxcroft, L.C., Spear, D., van Wilgen, N.J. \& McGeoch, Melodie A. (2019). Assessing the association between pathways of alien plant invaders and their impacts in protected areas. NeoBiota,43, 1-25. https://doi.org/10.3897/neobiota.43.29644.

Freeman, B.G., Scholer, M.N., Ruiz-Gutierrez, V. \& Fitzpatrick, J.W. (2018). Climate change causes upslope shifts and mountaintop extirpations in a tropical bird community. Proceedings of the National Academy of Sciences, 115, 11982-11987. https://doi.org/10.1073/pnas.1804224115.

Gelbard, J.L. \& Belnap, J. (2003). Roads as conduits for exotic plant invasions in a semiarid landscape. Conservation Biology,17, 420-432. https://doi.org/10.1046/j.1523-1739.2003.01408.x

Gillet, F., Mauchamp, L., Badot, P.-M. \& Mouly, A. (2016). Recent changes in mountain grasslands: a vegetation resampling study.Ecol Evol, 6, 2333-2345. https://doi.org/10.1002/ece3.1987.

Gobiet, A., Kotlarski, S., Beniston, M., Heinrich, G., Rajczak, J. \& Stoffel, M. (2014). 21st century climate change in the European Alps-A review. Science of the Total Environment, 493,1138-1151. https://doi.org/10.1016/j.scitotenv.2013.07.050.

Guisan, A., Broennimann, O., Buri, A., Cianfrani, C., D’Amen, M., Di Cola, V., Fernandes, R., Gray, S., Mateo, R.G., Pinto, E., Pradervand, J.-N., Scherrer, D., von Däniken, I., Yashiro, E. \& Vittoz, P. (2019). Climate change impact on mountain biodiversity. Biodiversity and climate change: Transforming the biosphere (eds T.E. Lovejoy \& L. Hannah), pp. 221-223. Yale University Press.

Guo, F., Lenoir, J. \& Bonebrake, T.C. (2018). Land-use change interacts with climate to determine elevational species redistribution. Nature Communications, 9, 1315. https://doi.org/10.1038/s41467-018-03786-9.

Haider, S., Kueffer, C., Bruelheide, H., Seipel, T., Alexander, J.M., Rew, L.J., Arévalo, J.R., Cavieres, L.A., McDougall, K.L., Milbau, A., Naylor, B.J., Speziale, K. \& Pauchard, A. (2018). Mountain roads and non- 
native species modify elevational patterns of plant diversity. Global Ecology and Biogeography, 27, 667-678. https://doi.org/10.1111/geb.12727.

Haider, S., Kueffer, C., Edwards, P.J. \& Alexander, J.M. (2012). Genetically based differentiation in growth of multiple non-native plant species along a steep environmental gradient. Oecologia,170, 89-99. https://doi.org/10.1007/s00442-012-2291-2.

Jakobs, G., Kueffer, C. \& Daehler, C.C. (2010). Introduced weed richness across altitudinal gradients in Hawai'i: humps, humans and water-energy dynamics. Biological Invasions, 12,4019-4031. https://doi.org/10.1007/s10530-010-9816-6.

Jetz, W., McGeoch, M.A., Guralnick, R., Ferrier, S., Beck, J., Costello, M.J., Fernandez, M., Geller, G.N., Keil, P., Merow, C., Meyer, C., Muller-Karger, F.E., Pereira, H.M., Regan, E.C., Schmeller, D.S. \& Turak, E. (2019). Essential biodiversity variables for mapping and monitoring species populations. Nature Ecology E Evolution,3, 539-551. https://doi.org/10.1038/s41559-019-0826-1.

Kadmon, R., Farber, O. \& Danin, A. (2004). Effect of roadside bias on the accuracy of predictive maps produced by bioclimatic models.Ecological Applications, 14, 401-413. https://doi.org/10.1890/02-5364.

Khaliq, I. (2019). Range expansion of Phytophthora, particularlyPhytophthora cinnamomi into colder environments: adaptation, a changing environment or both? PhD thesis, Murdoch University.

Kindt, R. (2020). WorldFlora: An R package for exact and fuzzy matching of plant names against the World Flora Online taxonomic backbone data.Applications in Plant Sciences, 8, e11388. https://doi.org/10.1002/aps3.11388.

Korner, C. \& Spehn, E. (2002). Mountain Biodiversity. A Global Assessment . The Parthenon Publishing Group, London - New York.

Kueffer, C., Daehler, C., Dietz, H., McDougall, K., Parks, C., Pauchard, A., Rew, L. \& Consortium, M. (2014). The Mountain Invasion Research Network (MIREN). Linking local and global scales for addressing an ecological consequence of global change. Gaia-Ecological Perspectives for Science and Society, 23, 263-265. https://doi.org/10.14512/gaia.23.3.11.

Kuhn, P., Ratier Backes, A., Romermann, C., Bruelheide, H. \& Haider, S. (2020). Contrasting patterns of intraspecific trait variability in native and non-native plant species along an elevational gradient on Tenerife, Canary Islands. Annals of Botany . https://doi.org/10.1093/aob/mcaa067.

Lembrechts, J.J., Alexander, J.M., Cavieres, L.A., Haider, S., Lenoir, J., Kueffer, C., McDougall, K., Naylor, B.J., Nunez, M.A., Pauchard, A., Rew, L.J., Nijs, I. \& Milbau, A. (2017). Mountain roads shift native and non-native plant species' ranges. Ecography, 40,353-364. https://doi.org/10.1111/ecog.02200.

Lembrechts, J.J., Lenoir, J., Roth, N., Hattab, T., Milbau, A., Haider, S., Pellissier, L., Pauchard, A., Ratier Backes, A., Dimarco, R.D., Nunez, M.A., Aalto, J. \& Nijs, I. (2019). Comparing temperature data sources for use in species distribution models: From in-situ logging to remote sensing. Global Ecology and Biogeography, 28,1578-1596. https://doi.org/10.1111/geb.12974.

Lembrechts, J.J., Milbau, A. \& Nijs, I. (2014). Alien roadside species more easily invade alpine than lowland plant communities in a subarctic mountain ecosystem. PLoS ONE, 9, e89664. https://doi.org/10.1371/journal.pone.0089664.g001.

Lenoir, J., Gegout, J.-C., Guisan, A., Vittoz, P., Wohlgemuth, T., Zimmermann, N.E., Dullinger, S., Pauli, H., Willner, W. \& Svenning, J.-C. (2010). Going against the flow: potential mechanisms for unexpected downslope range shifts in a warming climate.Ecography, 33, 295-303. https://doi.org/10.1111/j.16000587.2010.06279.x.

Lenoir, J., Gegout, J.C., Marquet, P.A., de Ruffray, P. \& Brisse, H. (2008). A significant upward shift in plant species optimum elevation during the 20th century. Science, 320, 1768-1771. 
https://doi.org/10.1126/science.1156831.

Liedtke, R., Barros, A., Essl, F., Lembrechts, J.J., Wedegartner, R.E.M., Pauchard, A. \& Dullinger, S. (2020). Hiking trails as conduits for the spread of non-native species in mountain areas. Biological Invasions, 22, 1121-1134. https://doi.org/10.1007/s10530-019-02165-9.

MacDonald, D., Crabtree, J.R., Wiesinger, G., Dax, T., Stamou, N., Fleury, P., Gutierrez Lazpita, J. \& Gibon, A. (2000). Agricultural abandonment in mountain areas of Europe: Environmental consequences and policy response. Journal of Environmental Management,59, 47-69. https://doi.org/10.1006/jema.1999.0335.

Maestre, F.T. \& Eisenhauer, N. (2019). Recommendations for establishing global collaborative networks in soil ecology. SOIL ORGANISMS,91, 73-85. https://doi.org/10.25674/so91iss3pp73.

Martin-Lopez, B., Leister, I., Lorenzo Cruz, P., Palomo, I., Gret-Regamey, A., Harrison, P.A., Lavorel, S., Locatelli, B., Luque, S. \& Walz, A. (2019). Nature's contributions to people in mountains: A review. PLoS ONE, 14, e0217847. https://doi.org/10.1371/journal.pone.0217847.

McDougall, K.L., Alexander, J.M., Haider, S., Pauchard, A., Walsh, N.G. \& Kueffer, C. (2011a). Alien flora of mountains: global comparisons for the development of local preventive measures against plant invasions.Diversity and Distributions, 17, 103-111. https://doi.org/10.1111/j.1472-4642.2010.00713.x.

McDougall, K.L., Khuroo, A.A., Loope, L.L., Parks, C.G., Pauchard, A., Reshi, Z.A., Rushworth, I. \& Kueffer, C. (2011b). Plant invasions in mountains: Global lessons for better management. Mountain Research and Development, 31, 380-387.

McDougall, K.L., Lembrechts, J., Rew, L.J., Haider, S., Cavieres, L.A., Kueffer, C., Milbau, A., Naylor, B.J., Nunez, M.A., Pauchard, A., Seipel, T., Speziale, K.L., Wright, G.T. \& Alexander, J.M. (2018). Running off the road: roadside non-native plants invading mountain vegetation. Biological Invasions, 20, 3461-3473. https://doi.org/10.1007/s10530-018-1787-z.

Meijer, J.R., Huijbregts, M.A.J., Schotten, K.C.G.J. \& Schipper, A.M. (2018). Global patterns of current and future road infrastructure.Environmental Research Letters, 13, 064006. https://doi.org/10.1088/1748$9326 /$ aabd 42 .

Mengist, W., Soromessa, T. \& Legese, G. (2020). Ecosystem services research in mountainous regions: A systematic literature review on current knowledge and research gaps. Science of the Total Environment, 702, 134581. https://doi.org/10.1016/j.scitotenv.2019.134581.

Mirtl, M., T. Borer, E., Djukic, I., Forsius, M., Haubold, H., Hugo, W., Jourdan, J., Lindenmayer, D., McDowell, W.H., Muraoka, H., Orenstein, D.E., Pauw, J.C., Peterseil, J., Shibata, H., Wohner, C., Yu, X. \& Haase, P. (2018). Genesis, goals and achievements of Long-Term Ecological Research at the global scale: A critical review of ILTER and future directions. Science of the Total Environment,626, 1439-1462. https://doi.org/10.1016/j.scitotenv.2017.12.001.

Morueta-Holme, N., Engemann, K., Sandoval-Acuna, P., Jonas, J.D., Segnitz, R.M. \& Svenning, J.-C. (2015). Strong upslope shifts in Chimborazo's vegetation over two centuries since Humboldt.Proceedings of the National Academy of Sciences of the United States of America, 112, 12741-12745. https://doi.org/10.1073/pnas.1509938112.

Mullerova, J., Vitkova, M. \& Vitek, O. (2011). The impacts of road and walking trails upon adjacent vegetation: Effects of road building materials on species composition in a nutrient poor environment.Science of the Total Environment, 409, 3839-3849. https://doi.org/10.1016/j.scitotenv.2011.06.056.

Munoz, A.A. \& Cavieres, L.A. (2008). The presence of a showy invasive plant disrupts pollinator service and reproductive output in native alpine species only at high densities. Journal of Ecology,96, 459-467. https://doi.org/10.1111/j.1365-2745.2008.01361.x. 
Munoz, A.A. \& Cavieres, L.A. (2019). Sharing of pollinators between the invasive Taraxacum officinale and co-flowering natives is not related to floral similarity in the high-Andes. Flora,261, 151491. https://doi.org/10.1016/j.flora.2019.151491.

Nogues-Bravo, D., Araujo, M.B., Errea, M.P. \& Martinez-Rica, J.P. (2007). Exposure of global mountain systems to climate warming during the 21st century. Global Environmental Change, 17,420-428. https://doi.org/10.1016/j.gloenvcha.2006.11.007.

Nunez, M.A., Barlow, J., Cadotte, M., Lucas, K., Newton, E., Pettorelli, N. \& Stephens, P.A. (2019). Assessing the uneven global distribution of readership, submissions and publications in applied ecology: Obvious problems without obvious solutions. Journal of Applied Ecology,56, 4-9. https://doi.org/10.1111/13652664.13319.

Nunez, M.A., Chiuffo, M.C., Torres, A., Paul, T., Dimarco, R.D., Raal, P., Policelli, N., Moyano, J., Garcia, R.A., van Wilgen, B.W., Pauchard, A. \& Richardson, D.M. (2017). Ecology and management of invasive Pinaceae around the world: progress and challenges. Biological Invasions, 19, 3099-3120. https://doi.org/10.1007/s10530-017-1483-4.

Pauli, H., Gottfried, M., Dullinger, S., Abdaladze, O., Akhalkatsi, M., Alonso, J.L.B., Coldea, G., Dick, J., Erschbamer, B., Calzado, R.F., Ghosn, D., Holten, J.I., Kanka, R., Kazakis, G., Kollar, J., Larsson, P., Moiseev, P., Moiseev, D., Molau, U., Mesa, J.M., Nagy, L., Pelino, G., Puşcaş, M., Rossi, G., Stanisci, A., Syverhuset, A.O., Theurillat, J.-P., Tomaselli, M., Unterluggauer, P., Villar, L., Vittoz, P. \& Grabherr, G. (2012). Recent plant diversity changes on Europe's mountain summits. Science, 336, 353-355. https://doi.org/10.1126/science.1219033.

Pauli, H., Gottfried, M., Lamprecht, A., Niessner, S., Rumpf, S., Winkler, M., Steinbauer, K. \& Grabherr, G. (2015). The GLORIA field manual - standard Multi-Summit approach, supplementary methods and extra approaches., pp. 137. GLORIA-Coordination, Austrian Academy of Sciences \& University of Natural Resources and Life Sciences, Vienna, Austria.

Payne, D., Spehn, E.M., Prescott, G.W., Geschke, J., Snethlage, M.A. \& Fischer, M. (2020). Mountain biodiversity is central to sustainable development in mountains and beyond. One Earth, 3,530-533. https://doi.org/10.1016/j.oneear.2020.10.013.

Pecl, G.T., Araújo, M.B., Bell, J.D., Blanchard, J., Bonebrake, T.C., Chen, I.-C., Clark, T.D., Colwell, R.K., Danielsen, F., Evengård, B., Falconi, L., Ferrier, S., Frusher, S., Garcia, R.A., Griffis, R.B., Hobday, A.J., Janion-Scheepers, C., Jarzyna, M.A., Jennings, S., Lenoir, J., Linnetved, H.I., Martin, V.Y., McCormack, P.C., McDonald, J., Mitchell, N.J., Mustonen, T., Pandolfi, J.M., Pettorelli, N., Popova, E., Robinson, S.A., Scheffers, B.R., Shaw, J.D., Sorte, C.J.B., Strugnell, J.M., Sunday, J.M., Tuanmu, M.N., Vergés, A., Villanueva, C., Wernberg, T., Wapstra, E. \& Williams, S.E. (2017). Biodiversity redistribution under climate change: Impacts on ecosystems and human well-being. Science, 355, eaai9214. https://doi.org/10.1126/science.aai9214.

Pellissier, L., Anzini, M., Maiorano, L., Dubuis, A., Pottier, J., Vittoz, P. \& Guisan, A. (2013). Spatial predictions of land-use transitions and associated threats to biodiversity: the case of forest regrowth in mountain grasslands. Applied Vegetation Science,16, 227-236. https://doi.org/10.1111/j.1654-109X.2012.01215.x.

Pepin, N., Bradley, R.S., Diaz, H.F., Baraer, M., Caceres, E.B., Forsythe, N., Fowler, H., Greenwood, G., Hashmi, M.Z., Liu, X.D., Miller, J.R., Ning, L., Ohmura, A., Palazzi, E., Rangwala, I., Schoener, W., Severskiy, I., Shahgedanova, M., Wang, M.B., Williamson, S.N. \& Yang, D.Q. (2015). Elevation-dependent warming in mountain regions of the world. Nature Climate Change, 5, 424-430. https://doi.org/10.1038/nclimate2563.

Peters, M.K., Hemp, A., Appelhans, T., Becker, J.N., Behler, C., Classen, A., Detsch, F., Ensslin, A., Ferger, S.W., Frederiksen, S.B., Gebert, F., Gerschlauer, F., Gütlein, A., Helbig-Bonitz, M., Hemp, C., Kindeketa, W.J., Kühnel, A., Mayr, A.V., Mwangomo, E., Ngereza, C., Njovu, H.K., Otte, I., Pabst, H., Renner, M., Röder, J., Rutten, G., Schellenberger Costa, D., Sierra-Cornejo, N., Vollstädt, M.G.R., Dulle, H.I., Eardley, 
C.D., Howell, K.M., Keller, A., Peters, R.S., Ssymank, A., Kakengi, V., Zhang, J., Bogner, C., BöhningGaese, K., Brandl, R., Hertel, D., Huwe, B., Kiese, R., Kleyer, M., Kuzyakov, Y., Nauss, T., Schleuning, M., Tschapka, M., Fischer, M. \& Steffan-Dewenter, I. (2019). Climate-land-use interactions shape tropical mountain biodiversity and ecosystem functions. Nature, 568,88-92. https://doi.org/10.1038/s41586-019-1048$\mathrm{z}$.

Petitpierre, B., McDougall, K., Seipel, T., Broennimann, O., Guisan, A. \& Kueffer, C. (2016). Will climate change increase the risk of plant invasions into mountains? Ecological Applications, 26,530-544. https://doi.org/10.1890/14-1871.1.

Pickering, C. \& Barros, A. (2012). Mountain environments and tourism. The Routledge Handbook of Tourism and the Environment (eds A. Holden \& D. Fennell), pp. 183-191. Routledge, London.

Pollnac, F., Seipel, T., Repath, C. \& Rew, L.J. (2012). Plant invasion at landscape and local scales along roadways in the mountainous region of the Greater Yellowstone Ecosystem. Biological Invasions,14, 17531763. https://doi.org/10.1007/s10530-012-0188-y.

Randin, C.F., Ashcroft, M.B., Bolliger, J., Cavender-Bares, J., Coops, N.C., Dullinger, S., Dirnböck, T., Eckert, S., Ellis, E., Fernández, N., Giuliani, G., Guisan, A., Jetz, W., Joost, S., Karger, D., Lembrechts, J., Lenoir, J., Luoto, M., Morin, X., Price, B., Rocchini, D., Schaepman, M., Schmid, B., Verburg, P., Wilson, A., Woodcock, P., Yoccoz, N. \& Payne, D. (2020). Monitoring biodiversity in the Anthropocene using remote sensing in species distribution models. Remote Sensing of Environment, 239, 111626. https://doi.org/10.1016/j.rse.2019.111626.

Rew, L.J., Brummer, T.J., Pollnac, F.W., Larson, C.D., Taylor, K.T., Taper, M.L., Fleming, J.D. \& Balbach, H.E. (2018). Hitching a ride: Seed accrual rates on different types of vehicles. Journal of Environmental Management, 206, 547-555. https://doi.org/10.1016/j.jenvman.2017.10.060.

Ross, C., Fildes, S. \& Millington, A. (2017). Land-use and land-cover change in the Paramo of South-Central Ecuador, 1979-2014. Land,6, 46. https://doi.org/10.3390/land6030046.

Rumpf, S.B., Hulber, K., Wessely, J., Willner, W., Moser, D., Gattringer, A., Klonner, G., Zimmermann, N.E. \& Dullinger, S. (2019). Extinction debts and colonization credits of non-forest plants in the European Alps. Nature Communications, 10, 4293. https://doi.org/10.1038/s41467-019-12343-x.

Seipel, T., Kueffer, C., Rew, L.J., Daehler, C.C., Pauchard, A., Naylor, B.J., Alexander, J.M., Edwards, P.J., Parks, C.G., Arevalo, J.R., Cavieres, L.A., Dietz, H., Jakobs, G., McDougall, K., Otto, R. \& Walsh, N. (2012). Processes at multiple scales affect richness and similarity of non-native plant species in mountains around the world. Global Ecology and Biogeography, 21, 236-246. https://doi.org/10.1111/j.14668238.2011.00664.x.

Spehn, E.M., Libermann, M. \& Korner, C. (2006). Land use change and mountain biodiversity. CRC Press, Andover, UK.

Steinbauer, M.J., Grytnes, J.-A., Jurasinski, G., Kulonen, A., Lenoir, J., Pauli, H., Rixen, C., Winkler, M., Bardy-Durchhalter, M., Barni, E., Bjorkman, A.D., Breiner, F.T., Burg, S., Czortek, P., Dawes, M.A., Delimat, A., Dullinger, S., Erschbamer, B., Felde, V.A., Fernandez-Arberas, O., Fossheim, K.F., Gomez-Garcia, D., Georges, D., Grindrud, E.T., Haider, S., Haugum, S.V., Henriksen, H., Herreros, M.J., Jaroszewicz, B., Jaroszynska, F., Kanka, R., Kapfer, J., Klanderud, K., Kuhn, I., Lamprecht, A., Matteodo, M., di Cella, U.M., Normand, S., Odland, A., Olsen, S.L., Palacio, S., Petey, M., Piscova, V., Sedlakova, B., Steinbauer, K., Stockli, V., Svenning, J.-C., Teppa, G., Theurillat, J.-P., Vittoz, P., Woodin, S.J., Zimmermann, N.E. \& Wipf, S. (2018). Accelerated increase in plant species richness on mountain summits is linked to warming. Nature, 556, 231-234. https://doi.org/10.1038/s41586-018-0005-6.

van Kleunen, M., Dawson, W., Essl, F., Pergl, J., Winter, M., Weber, E., Kreft, H., Weigelt, P., Kartesz, J., Nishino, M., Antonova, L.A., Barcelona, J.F., Cabezas, F.J., Cardenas, D., Cardenas-Toro, J., Castano, N., Chacon, E., Chatelain, C., Ebel, A.L., Figueiredo, E., Fuentes, N., Groom, Q.J., Henderson, L., Inderjit, 
Kupriyanov, A., Masciadri, S., Meerman, J., Morozova, O., Moser, D., Nickrent, D.L., Patzelt, A., Pelser, P.B., Baptiste, M.P., Poopath, M., Schulze, M., Seebens, H., Shu, W.-s., Thomas, J., Velayos, M., Wieringa, J.J. \& Pyšek, P. (2015). Global exchange and accumulation of non-native plants.Nature, 525, 100-103. https://doi.org/10.1038/nature14910.

Vorstenbosch, T., Essl, F. \& Lenzner, B. (2020). An uphill battle? The elevational distribution of alien plant species along rivers and roads in the Austrian Alps. NeoBiota, 63, 1-24. https://doi.org/10.3897/neobiota.63.55096.

Walsh, N.G. \& McDougall, K.L. (2018). A new species of Poa L. (Poaceae) from Kosciuszko National Park, New South Wales.Muelleria, 36, 92-96.

Wang, Y., Wu, N., Kunze, C., Long, R. \& Perlik, M. (2019). Drivers of change to mountain sustainability in the Hindu Kush Himalaya. The Hindu Kush Himalaya Assessment: Mountains, climate change, sustainability and people (eds P. Wester, A. Mishra, A. Mukherji \& A.B. Shrestha), pp. 17-56. Springer International Publishing, Cham.

Wasowicz, P. (2016). Non-native species in the vascular flora of highlands and mountains of Iceland. PeerJ, 4, e1559. https://doi.org/10.7717/peerj.1559.

Weigelt, P., König, C. \& Kreft, H. (2020). GIFT - A Global Inventory of Floras and Traits for macroecology and biogeography. Journal of Biogeography, 47, 16-43. https://doi.org/10.1111/jbi.13623.

Zong, S., Jin, Y., Xu, J., Wu, Z., He, H., Du, H. \& Wang, L. (2016). Nitrogen deposition but not climate warming promotes Deyeuxia angustifolia encroachment in alpine tundra of the Changbai Mountains, Northeast China. Science of the Total Environment, 544,85-93. https://doi.org/10.1016/j.scitotenv.2015.11.144. 